Aim of the study: The purpose of this retrospective study is to evaluate the clinicopathological features and treatment results of male breast cancer presented to our tertiary referral center.

Material and methods: Between January 1998 and December 2005, a total of 39 men with breast cancer treated at Alexandria Main University Hospital and their medical records were reviewed.

Results: The median age of patients was 59 years. Only 3 (7.7\%) patients had positive family history. All patients presented by breast swellings that were associated with axillary mass in about one third of them. Around $80 \%$ had hormone receptor positive (estrogen and/or progesterone receptors). Two third of patients had advanced T-stage (T3 and T4). Left sided breast cancer occurred in $51.3 \%$. Infiltrating ductal carcinoma was the most common type of histology encountered and grade 2 was the predominant grade of tumor. Modified radical mastectomy was the most common (87.2\%) type of surgery done followed by chemotherapy for 32 patients and loco-regional radiotherapy for $20 \mathrm{pa}$ tients. Tamoxifen was administered in 31 patients. Distant relapse occurred in 7 patients $(17.9 \%)$ and local recurrence occurred in 2 patients (5.1\%). The 5 -year disease-free survival (DFS) was $82 \%$ and the 5 -year overall survival (OS) rate was $84 \%$. Only negative axillary lymph node and positive hormone receptor status were significantly associated with favorable DFS and OS. T-stage, grade of tumor and type of chemotherapy given had no statistically significant impact on either DFS or OS.

Conclusions: Male breast cancer is still under-investigated and further researches are warranted.

Key words: breast cancer, male.

Contemp Oncol (Pozn) 2016; 20 (4): 335-340 DOI: $10.5114 /$ wo.2016.61855

\section{Male breast cancer: a clinicopathological study of an Egyptian population (Alexandria experience)}

\author{
Maher Soliman ${ }^{1}$, Marcin Hetnał ${ }^{2}$ \\ ${ }^{1}$ Oncology Department, Faculty of Medicine, Alexandria University, Alexandria, \\ Egypt \\ ${ }^{2}$ Amethyst Radiotherapy Centre, Krakow, Poland
}

\section{Introduction}

The incidence of male breast cancer (MBC) is low, constituting less than $1 \%$ of all breast cancer cases [1, 2]. In central and eastern Africa breast cancer rates are higher and reach $6 \%$ of cancers in men, which could be explained by hyperestrogenism due to endemic hepatic infectious disease [3]. A large epidemiological study has shown a growing incidence of male breast cancer of $1 \%$ in one year [1]. The male-to-female ratio of incidence in breast cancer is about $1 \%$ in western countries, but it was markedly higher in North Africa $-2.7 \%$ and even higher in Sub-Saharan countries $-4.9 \%$. Moreover, in Africa the age at diagnosis of breast cancer was seven years later in men than in women [4].

The most important risk factors are family history and mutations of BRCA. More than twice the proportion of males with breast cancer have a family history, compared with $7 \%$ in the overall male population [5].

Other important risk factors are: Klinefelter syndrome, oestrogen or testosterone use, orchitis/epididymitis, obesity, lack of exercise, and exposure to radiation [6].

Invasive ductal carcinoma constitute approximately $90 \%$ of breast cancers in men, whereas only $1.5 \%$ of cases are lobular cancers, compared to about $15 \%$ of cases in women, which could be explained by the lack of lobules and acini in male breast tissue $[5,7]$.

The most common type of male breast cancer is hormone receptor positive $-82 \%, 15 \%$ are human epidermal growth factor receptor 2 (HER2)-positive (young patients more likely), and $4 \%$ are triple negative. An interesting phenomenon is that non-Hispanic black males are more frequently triple negative - 9\% compared to Hispanic - $6 \%$ and non-Hispanic white - $3 \%$. A study has shown that non-Hispanic black males had the worst outcomes [8].

Optimal treatments are still vague, and further work is clearly needed to better understand this disease $[1-3,9,10]$.

The surgical, systemic, and radiation treatment of males with breast cancer are similar to the rules in the approach for women and depends on the extent of disease at presentation and other risk factors.

Due to the relative rarity of $\mathrm{MBC}$, prospective randomised trials are lacking, and management of $\mathrm{MBC}$ is based on either retrospective series or extrapolation from that of females $[1,11]$. Therefore, we try in this retrospective study to evaluate the clinicopathological features and treatment results of $M B C$ presented to our tertiary referral centre.

\section{Material and methods}

In this retrospective study, the medical files of 39 men with pathologically proven breast cancer, who presented to the Clinical Oncology department, 
Alexandria Main University Hospital during the period from January 1998 to December 2005, were reviewed. Patients with clinical evidence of distant metastases at the time of presentation have been excluded. Data regarding history and clinical presentation, investigations, and treatment received were collected and correlated to local recurrence, distant metastasis, and survival.

The overall survival (OS) was calculated from the date of diagnosis to the date of death or last follow-up. Disease-free survival (DFS) was defined as time from date

Table 1. Patients and disease characteristics of male breast cancer

\begin{tabular}{|c|c|}
\hline Characteristics & No. (\%) \\
\hline Age (median) & 59 years (range: $33-80)$ \\
\hline \multicolumn{2}{|l|}{ Family history } \\
\hline Positive & $3(7.7)$ \\
\hline Negative & $36(92.3)$ \\
\hline \multicolumn{2}{|l|}{ Side } \\
\hline Right & $19(48.7)$ \\
\hline Left & $20(51.3)$ \\
\hline \multicolumn{2}{|l|}{ Presentation } \\
\hline Breast mass & $39(100)$ \\
\hline Axillary swelling & $11(28.2)$ \\
\hline Nipple discharge & $6(15.4)$ \\
\hline \multicolumn{2}{|l|}{ T-Stage } \\
\hline $\mathrm{T} 1$ & $1(2.6)$ \\
\hline $\mathrm{T} 2$ & $10(25.6)$ \\
\hline T3 & $8(20.5)$ \\
\hline $\mathrm{T} 4$ & $20(51.3)$ \\
\hline \multicolumn{2}{|l|}{ N-Stage } \\
\hline Positive & $16(41)$ \\
\hline Negative & $18(46.2)$ \\
\hline Unknown & $5(12.8)$ \\
\hline \multicolumn{2}{|l|}{ Histology } \\
\hline IDC & $36(92.3)$ \\
\hline Others & $3(7.7)$ \\
\hline \multicolumn{2}{|l|}{ Grade } \\
\hline 1 & $1(2.6)$ \\
\hline 2 & $30(76.9)$ \\
\hline 3 & $2(5.1)$ \\
\hline Unknown & $6(15.4)$ \\
\hline \multicolumn{2}{|c|}{ Hormone receptor status } \\
\hline $\mathrm{ER}+$ and/or PR+ & $31(79.5)$ \\
\hline$E R-$ and $P R-$ & 7 (17.9) \\
\hline Unknown & $1(2.6)$ \\
\hline \multicolumn{2}{|l|}{ Surgery } \\
\hline Lumpectomy & $5(12.8)$ \\
\hline MRM & $34(87.2)$ \\
\hline
\end{tabular}

$I D C$ - infiltrating ductal carcinoma; MRM - modified radical mastectomy; ER oestrogen receptor; $P R$ - progesterone receptor of diagnosis to date of local recurrence or distant failure, depending on what occurred earlier. Patients without disease recurrence were censored at last follow-up.

Survival was estimated using the Kaplan-Meier product-limit method using SPSS (v. 22) software (SPSS Inc., Chicago, IL, USA). Patient and tumour characteristics, namely age, T-stage, grade of tumour, axillary lymph node (LN) status, and hormone receptor status, were studied to determine the effect of each variable on survival rates. The two-sided log-rank test was used to test the association between patient variables and survival. $P \leq 0.05$ was considered as significant.

\section{Results}

\section{Patients' characteristics}

Thirty-nine patients were included in this analysis. The median age of patients was 59 years (range: 33-80 years). Only three patients (7.7\%) had positive family history. All patients presented by breast mass and about one third of them had axillary mass. Only six patients experienced nipple discharge. Around $80 \%$ had positive hormone receptor (oestrogen and/or progesterone receptors). Two thirds of patients had advanced T-stage (T3 and T4). Left-sided breast cancer occurred in 51.3\%. Infiltrating ductal carcinoma (IDC) was the most common type of histology encountered, and grade 2 was the predominant grade of tumour. Table 1 shows the characteristics of the patients. Figures 1-6 shows paraffin and immunostained sections of two patients.

\section{Treatment}

The majority of patients (87.2\%) underwent modified radical mastectomy (MRM). Adjuvant chemotherapy CMF (cyclophosphamide, methotrexate, 5-fluorouracil) and CAF (cyclophosphamide, doxorubicin, 5-fluorouracil) regimens were given for 11 and 21 patients, respectively. Loco-regional radiotherapy was offered to 20 patients. Tamoxifen was administered in 31 patients as an adjuvant after chemotherapy and/or radiotherapy.

\section{Disease-free survival}

Seven patients (17.9\%) suffered a distant relapse and two patients suffered a local recurrence (5.1\%). The commonly involved sites were bone (four patients), lung (three patients), and liver (two patients; one patient developed multiple metastatic sites). The five-year DFS for the entire group was $82 \%$ (Fig. 7A). DFS at five years for axillary node-negative patients was $100 \%$ and for axillary node-positive patients was $44 \%(p=0.001)$. Patients with positive hormone receptors had significantly better fiveyear DFS (88\%) compared to those with negative hormone receptors $(25 \% ; p=0.000)$. T-stage $(p=0.541)$, grade $(p=0.835)$, and type of adjuvant chemotherapy received $(p=0.447)$ had no impact on the five-year DFS (Fig. 8).

\section{Overall survival}

The five-year overall survival rate of patients was $84 \%$ (Fig. 7B). In univariate analysis, patients with negative ax- 


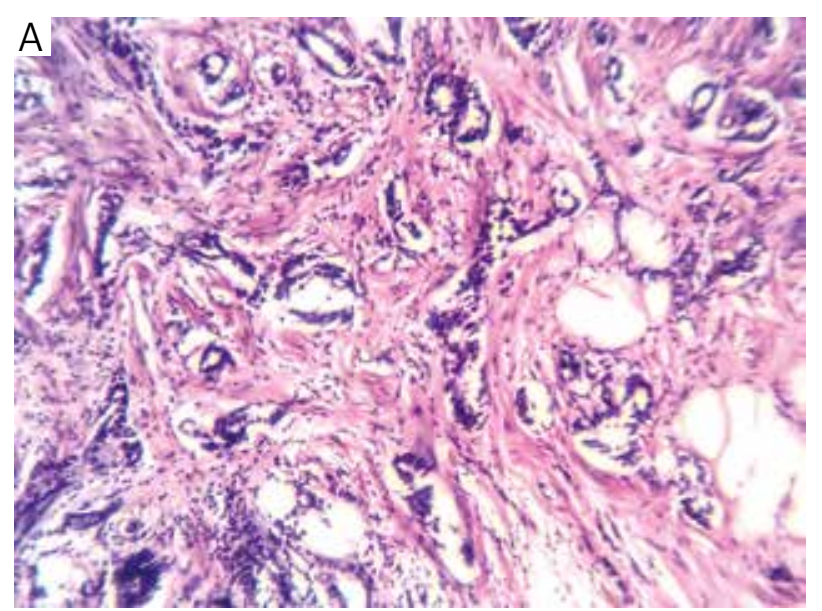

Fig. 1. A case of infiltrating ductal carcinoma of no special type (NST) Grade II showing streaks \& ductules of pleomorphic and hyperchromatic ductal carcinoma cells among collagenic stroma (H\&E, original magnification 200x)

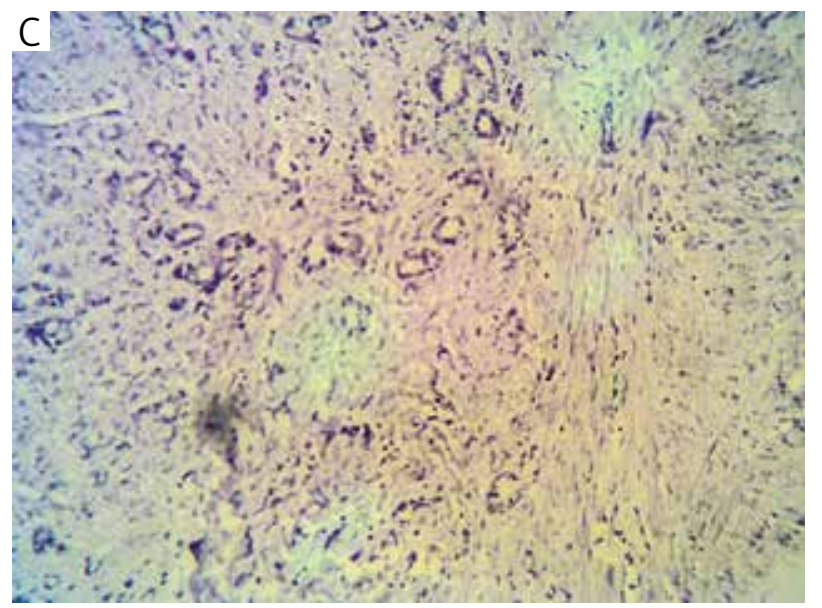

Fig. 3. Immunostained section for PR receptor showing weak nuclear staining in $20 \%$ of the malignant cell nuclei (original magnification 200x)

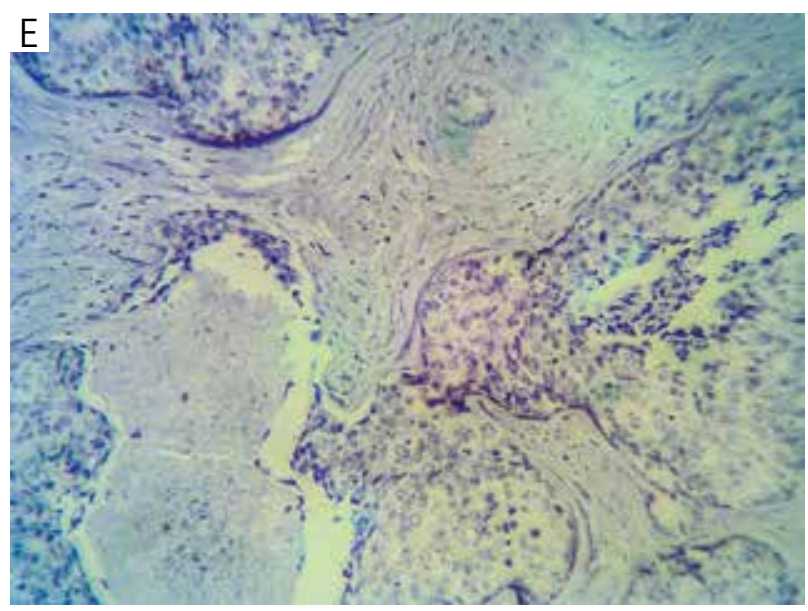

Fig. 5. immunostained section from ER receptor showing negative nuclear uptake in all malignant cells (original magnification 200x)

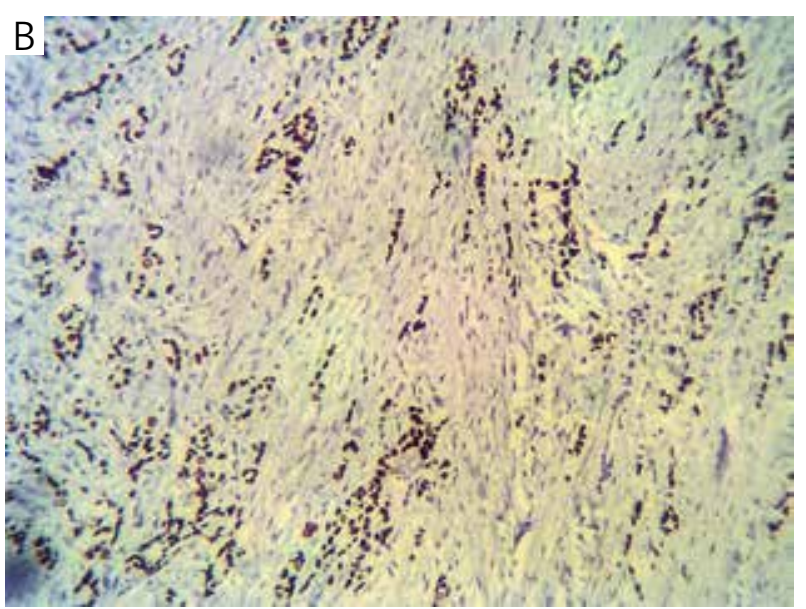

Fig. 2. Immunostained section for ER receptor showing a strong nuclear uptake in almost all of the malignant cell nuclei (original magnification 200x)

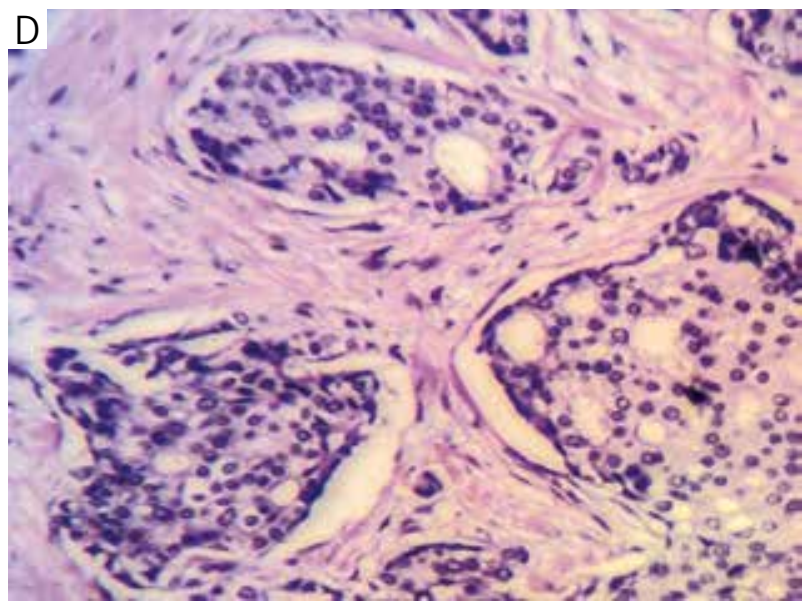

Fig. 4. Paraffin section for another case of infiltrating ductal carcinoma of no special type (NST) Grade II showing groups and nests of pleomorphic and hyperchomatic ductal carcinoma cells (original magnification 200x)

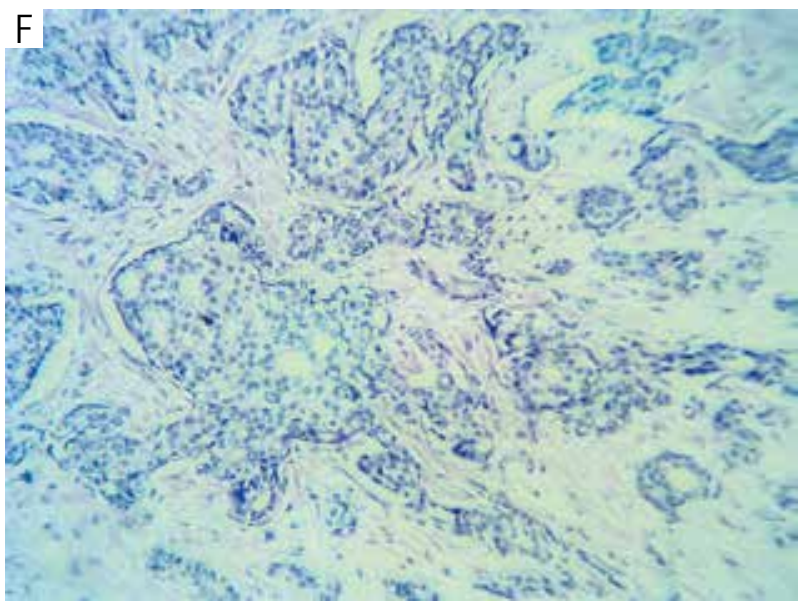

Fig. 6. Immunostaining for PR receptor showing negative nuclear uptake in all malignant cells (original magnification 200x) 

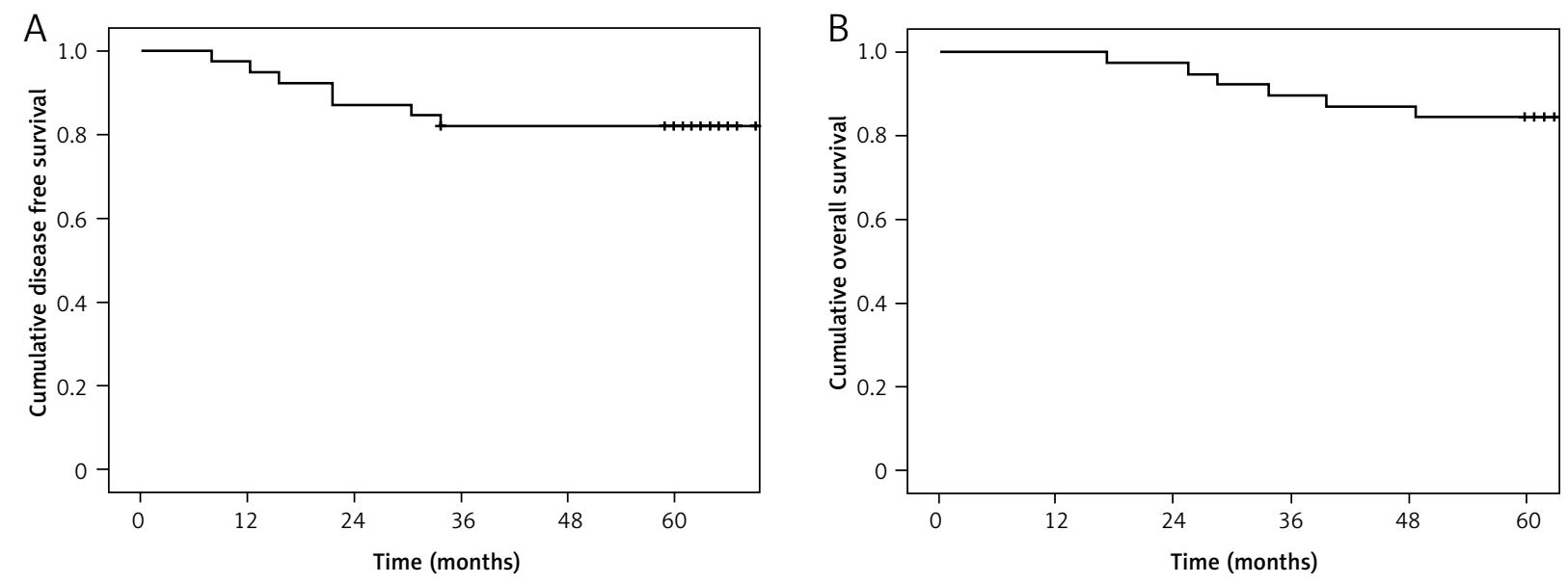

+ censored

Fig. 1. A) Disease-free survival and B) overall survival rates for men with breast cancer
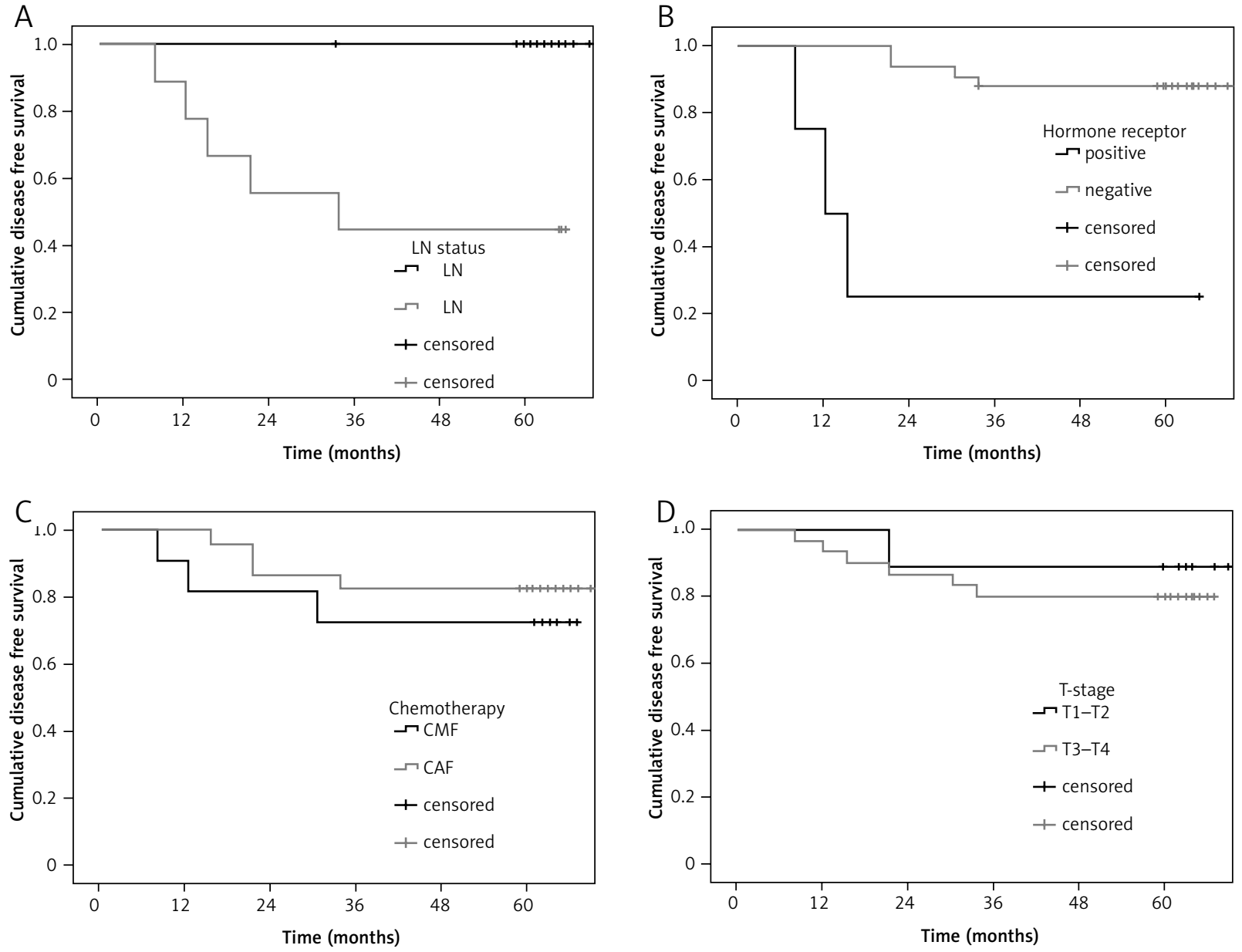

Fig. 2. Disease-free survival rates for men with breast cancer according to LN status (A), hormone receptor status (B), chemotherapy regimen (C), and T-stage (D) 
illary node had significantly better OS compared to those with positive axillary node $(p=0.001)$. The subset of patients with positive hormone receptors had significantly better five-year OS compared with those with negative hormone receptors $(p=0.000)$. There was no statistically significant difference in OS based on T-stage, grade of tumour, or type of chemotherapy given.

\section{Discussion}

The earliest recorded case of $M B C$ is described in the Edwin Smith papyrus from Egypt (3000-2500 BC); in modern times, the British physician John of Arderne is reported to be the first to discover this disease in a male patient in the $14^{\text {th }}$ century $[12,13]$. Male breast cancer, despite being increased in the last decades, is still a rare disease and under-evaluated [1]. Thus, collection of comprehensive data on the presentation and management of $\mathrm{MBC}$ may help to optimise the outcome of patients.

The median age of our patients was 59 years, which is consistent with that reported by Crichlow [11]. Unlike female breast cancer, the age at diagnosis in men had no impact on DFS or OS in our series, and this is agreement with that reported by Borgen et al. [14].

Consistent with literature $[1,15,16]$, we have demonstrated that men tend to have more advanced disease with larger tumour size and more frequent lymph node involvement (about $50 \%$ of our patients). This could be explained by the lack of a screening program (unlike for women), smaller breast tissue, unawareness of patients, and lack of expectation among treating physicians; furthermore, the stigma of cancer in general, and breast cancer (a disease of woman) in particular, make men seek medical advice later.

Men are significantly more likely to have hormone receptor-positive disease than women. Similar to that reported by Giordano et al. [1], $80 \%$ of men had hormone receptor-positive tumours in our series, compared with $67-76 \%$ in women $[9,17,18]$.

Oestrogen receptor is expressed in $75-97 \%$, progesterone receptor in $59-96 \%$, and HER2 in $1.7-29 \%$ in MBC in different series [19].

Surgery is the keystone in the treatment of MBC followed by adjuvant therapy [20-22]. Post-operative chemotherapy was given in about $80 \%$ of patients depending on the extent of tumour (T- \& N-stage), hormone receptor status, age, performance status of the patients, and associated co-morbidities. Adjuvant radiotherapy was applied in about half of our patients due to any of the following: involvement of the skin and/or pectoral muscle and areola, inadequate margins, and metastatic spread to the axillary lymph nodes. Tamoxifen was the only adjuvant hormonal therapy experienced in our patients with hormone receptor-positive disease.

The five-year survival rate of patients was $84 \%$, which is consistent with that reported by previous studies [2, 14]. Survival is comparable with reports form developed countries and higher than other series from Africa [23, 24]. Borgen et al. [14] found that the five-year OS was $85 \%$. Relapse-free survival at five years for axillary node-negative patients was $87 \%$ and for node-positive patients was $30 \%$. Five-year survival was $100 \%$ for the node-negative subset and $60 \%$ for the node-positive subset. Like in female breast cancer, we found that the most powerful predictors of outcome in men were axillary lymph nodes status and hormone receptors status. However, T-stage did not impact the survival because only one patient had T1, and we analysed T1 \& T2 together [20, 25].

The current study documents improved survival rates compared to those that have been historically reported for male breast cancer patients, and these may be a reflection of the proper adjuvant treatment received in most of our patients [21, 22, 26-29]. The survival figures reported are similar to currently accepted figures reported for female breast cancer $[2,14]$.

To our knowledge, this is the first trial from our heavily populated city with more than four million persons to address this issue. We know that our study has some limitations, being a retrospective trial with selection bias, small sample size, and a lack of information on risk factors such as testicular disease, benign breast conditions, and the Klinefelter syndrome. Moreover, pathological data regarding BRCA1, BRCA2, Her2/neu, and Ki-67 are not available [30]. Multivariate analysis was not performed to determine the independent effect of each variable in the presence of other variables.

In conclusion, MBC is very similar to female breast cancer but has certain unique features, which should be further explored in future research. In the absence of solid evidence, adjuvant treatment should be strongly considered and should be based on the greater base of knowledge available for carcinoma of the female breast.

\section{The authors declare no conflict of interest.}

\section{References}

1. Giordano SH, Cohen DS, Buzdar AU Perkins G, Hortobagyi GN. Breast carcinoma in men: A population based study. Cancer 2004; 101: 51-7.

2. Bagley CS, Wesley MN, Young RC, Lippman ME. Adjuvant chemotherapy in males with cancer of the breast. Am J Clin Oncol 1987; 10: $55-60$.

3. Sasco AJ, Lowenfels AB, Pasker-de Jong P. Review article: epidemiology of male breast cancer. A meta-analysis of published case-control studies and discussion of selected aetiological factors. Int J Cancer 1993; 53: 538-49.

4. Ndom P, Um G, Bell EM, et al. A meta-analysis of male breast cancer in Africa. Breast 2012; 21: 237-41.

5. Giordano SH, Buzdar AU, Hortobagyi GN. Breast cancer in men. Ann Intern Med 2002; 137: 678-87.

6. Ruddy KJ, Winer EP. Male breast cancer: Risk factors, biology, diagnosis, treatment, and survivorship. Ann Oncol 2013; 24: 1434-43.

7. Michaels BM, Nunn CR, Roses DF. Lobular carcinoma of the male breast. Surgery 1994; 115: 402-5.

8. Chavez-Macgregor M, Clarke CA, Lichtensztajn D, et al. Male breast cancer according to tumor subtype and race: a population-based study. Cancer 2013; 119: 1611-7.

9. Giordano $\mathrm{SH}$. A review of diagnosis and management of male breast cancer. Oncologist 2005; 10: 471-9.

10. Dawson PJ, Paine TM, Wolman SR. Immunocytochemical characterization of male breast cancer. Mod Pathol 1992; 5: 621-5. 
11. Crichlow RW. Carcinoma of the male breast. Surg Gynecol Obstet 1972; 134: 1011-19.

12. Redlich PN, Donegan WL. Carcinoma of the breast in men. In: Winchester DJ, Winchester DP, Decker BC (eds.). American Cancer Society Atlas of Clinical Oncology Breast Cancer. Inc Hamilton, London 2000; 239-52.

13. Shah S, Bhattacharyya S, Gupta A, Ghosh A, Basak S. Male breast cancer: A clinicopathologic study of 42 patients in Eastern India. Indian J Surg Oncol 2012; 3: 245-9.

14. Borgen PI, Wong Gl, Vlamis V, et al. Current management of male breast cancer: A review of 104 cases. Ann Surg 1992; 215: 451-9.

15. Heller KS, Rosen PP, Schottenfeld D, Ashikari R, Kinne DW. Male breast cancer: a clinicopathologic study of 97 cases. Ann Surg 1978; 188: 60-5.

16. Siddiqui T, Weiner R, Moreb J, Marsh RD. Cancer of the male breast with prolonged survival. Cancer 1988; 62: 1632-6.

17. Wick MR, Sayadi H, Ritter JH, Hill DA, Reddy VB, Gattuso P. Lowstage carcinoma of the male breast. A histologic, immunohistochemical, and flow cytometric comparison with localized female breast carcinoma. Am J Clin Pathol 1999; 111: 59-69.

18. Willsher PC, Leach IH, Ellis IO, Bell JA, Elston CW, Bourke JB, Blamey RW, Robertson JF. Male breast cancer: pathological and immunohistochemical features. Anticancer Res 1997; 17: 2335-8.

19. Zografos E, Gazouli M, Tsangaris G, Marinos E. The significance of proteomic biomarkers in male breast cancer. Cancer Genomics Proteomics 2016; 13: 183-90.

20. Cutuli B, Lacroze M, Dilhuydy JM, et al. Male breast cancer: results of the treatments and prognostic factors in 397 cases. Eur J Cancer 1995; 31A: 1960-4.

21. Scott-Conner CE, Jochimsen PR, Menck HR, Winchester DJ. An analysis of male and female breast cancer treatment and survival among demographically identical pairs of patients. Surgery 1999; 126: 775-80.

22. Yildirim E, Berberoglu U. Male breast cancer: a 22-year experience. Eur J Surg Oncol 1998; 24: 548-52.

23. Soliman AA, Denewer AT, El-Sadda W, Abdel-Aty AH, Refky B. A retrospective analysis of survival and prognostic factors of male breast cancer from a single centre. BMC Cancer 2014; 14: 227.

24. Ahmed A, Ukwenya Y, Abdullahi A, Muhammad I. Management and outcomes of male breast cancer in Zaria, Nigeria. Int J Breast Cancer 2012; 2012: 845143.

25. Figg WD 2nd, Cook K, Clarke R. Aromatase inhibitor plus ovarian suppression as adjuvant therapy in premenopausal women with breast cancer. Cancer Biol Ther 2014; 15: 1586-7.

26. Ramantanis G, Besbeas S, Garas JG. Breast cancer in the male: a report of 138 cases. World J Surg 1980; 4: 621-4.

27. Ajaxi DVS, Osegbe DN, Ademiluvi SA. Carcinoma of the male breast in West Africans and a review of world literature. Cancer 1982; 50: 1664-7.

28. Appelqvist P, Salmo M. Prognosis in carcinoma of the male breast. Acta Chir Scand 1982; 148: 499-502.

29. Axelsson J, Anderson A. Cancer of the male breast. World J Surg 1983; 7: 281-7.

30. Kwiatkowska E, Teresiak M, Filas V, Karczewska A, Bręborowicz D, Mackiewicz A. BRCA2 mutations and androgen receptor expression as independent predictors of outcome of male breast cancer patients. Clin Cancer Res 2003; 4452-9.

\section{Address for correspondence}

\section{Marcin Hetnał}

Amethyst Radiotherapy Centre

Złotej Jesieni 1

31-826 Krakow, Poland

e-mail: marcin.hetnal@gmail.com

Submitted: 13.03 .2016

Accepted: $\quad 1.08 .2016$ 